\title{
The Need to Develop an Individualized Intervention for Mathematics Anxiety
}

\author{
Ahmed A. Moustafa ${ }^{1,2}$, Ahmed A. Al-Emadi ${ }^{3}$ and Ahmed M. Megreya ${ }^{3 *}$ \\ ${ }^{1}$ School of Psychology, Western Sydney University, Sydney, NSW, Australia, ${ }^{2}$ Department of Human Anatomy and \\ Physiology, The Faculty of Health Sciences, University of Johannesburg, Johannesburg, South Africa, ${ }^{3}$ Department of \\ Psychological Sciences, College of Education, Qatar University, Doha, Qatar
}

Keywords: mathematics anxiety, intervention, cognitive behavioral therapy, math education, individualized treatment

\section{INTRODUCTION}

Mathematics anxiety is prevalent in many societies around the world, ranging from 30 to $70 \%$ (for a review, see Betz, 1978; Dowker et al., 2016). More than 30\% of 15-year-old students across the Organization for Economic Co-operation and Development (OECD) countries reported having mathematics anxiety (OECD, 2013). Several studies have shown that mathematics anxiety is related to both mathematics performance and joining Science, Technology, Engineering, and Mathematics (STEM)-related careers (Moustafa et al., 2017, 2020; Zhang et al., 2019). While most prior studies on the link between mathematics anxiety and interest in STEM careers are correlational, it is plausible to assume that mathematics anxiety at early school years (Krinzinger et al., 2009) could have led

Edited by: Pina Filippello,

University of Messina, Italy

Reviewed by: Alberto Sardella

University of Messina, Italy Juanna Joensen, University of Chicago, United States

${ }^{*}$ Correspondence: Ahmed M. Megreya amegreya@qu.edu.qa

Specialty section:

This article was submitted to Educational Psychology, a section of the journal

Frontiers in Psychology

Received: 10 June 2021 Accepted: 07 September 2021 Published: 20 October 2021

Citation:

Moustafa AA, Al-Emadi AA and Megreya AM (2021) The Need to Develop an Individualized Intervention for Mathematics Anxiety.

Front. Psychol. 12:723289. doi: 10.3389/fpsyg.2021.723289 to low interest in STEM careers later in life. Importantly, there are almost no existing approved interventions for mathematics anxiety. The purpose of this current opinion article is to highlight the need to develop an individualized intervention that targets factors leading to mathematics anxiety in students

\section{MATHEMATICS ANXIETY}

Dreger and Aiken (1957) and Gough (1954) coined the term mathematic anxiety to refer to a feeling of tension, apprehension, or even dread interfering with number manipulation and mathematical problem solving (Ashcraft and Faust, 1994; Ashcraft, 2002; Moustafa et al., 2017; Alkan, 2018; Lukowski et al., 2019a,b). Mathematics anxiety was found to be related to the complexity of mathematics activities (Faust et al., 1996; Namkung et al., 2019) and it is separate from other anxieties such as science anxiety (Megreya et al., 2021). Artemenko et al. (2015) found that mathematics anxiety can even occur before the exposure to mathematics activities, which then interferes with learning mathematical materials in the classroom.

\section{THE IMPACT OF MATHEMATICS ANXIETY ON MATHEMATICS PERFORMANCE AND STEM-RELATED CAREERS}

Mathematics performance has been measured in many different ways using, for example, mathematics tests and Grade Point Average (GPA) (Hart and Ganley, 2019). Several studies have found that there is a negative relationship between mathematics anxiety and mathematics performance (Ma, 1999; Hart and Ganley, 2019; Namkung et al., 2019; Zhang et al., 2019). Furthermore, mathematics anxiety was also found to impact STEM-related attitudes and careers. According to Tsupros et al. (2009), "STEM education is an interdisciplinary approach to learning 
where rigorous academic concepts are coupled with realworld lessons as students apply science, technology, engineering, and math in contexts that make connections between school, community, work, and the global enterprise enabling the development of STEM literacy and with it the ability to compete in the new economy." According to Brown et al. (2011), STEM education has been defined as " a standards-based, meta-discipline residing at the school level where all teachers, especially science, technology, engineering, and math (STEM) teachers, teach an integrated approach to teaching and learning, where disciplinespecific content is not divided, but addressed and treated as one lively, fluid study." In an epidemiological study conducted in the US using 3,000 students, Ahmed (2018) found that mathematics anxiety was related to the avoidance of STEM career choices. Further, several studies have shown that mathematics anxiety impacts successful education and future employment (Hembree, 1990; Ashcraft and Krause, 2007).

\section{FACTORS UNDERLYING MATHEMATICS ANXIETY}

Students may develop mathematics anxiety for different reasons (Hartwright et al., 2018; McDonough and Ramirez, 2018). For example, some students may develop mathematics anxiety due to having general trait anxiety (Baloglu, 1999; Kazelskis et al., 2000; Cipora et al., 2015; O’Leary et al., 2017; Paechter et al., 2017; Lauer et al., 2018), which is a relatively a stable individual disposition and related to feeling anxiety across different situations and in different environments. Students with high trait anxiety may experience anxiety upon exposure to complex mathematical problems.

General trait anxiety was found to be related to emotional dysregulation (Amstadter, 2008). Accordingly, individual differences in emotional regulation were also related to the development of mathematics anxiety (Klein et al., 2019). Further, some studies have shown that emotional dysregulation is related to low mathematics performance and mathematics anxiety (Brunyé et al., 2013; Artemenko et al., 2015; Pizzie and Kraemer, 2018; Klein et al., 2019). The link between emotional dysregulation and mathematics anxiety can be explained as follows: Mathematics anxiety is related to an increase in emotional feelings. However, a weak emotional regulation mechanism cannot provide a cognitive control system to manage such intense feelings, leading to the expression of mathematics anxiety (for discussion see Turk et al., 2005; Suveg et al., 2018).

In addition, mathematics anxiety in some individuals may be related to negative mathematics beliefs, that is, beliefs about one's mathematics capabilities (e.g., girls are not good at math, I am not a math person, math is so confusing, or math is scary, Bieg et al., 2015; Buckley et al., 2016; Ramirez et al., 2018). Along these lines, studies found that low self-esteem (Das et al., 2014; Jameson and Fusco, 2014; Balmeo and Fabella, 2018) and low self-efficacy (i.e., belief in one's ability to succeed, Walsh, 2008; Russo et al., 2014) are related to increased mathematics anxiety and reduced mathematics performance. This is probably related to students' beliefs on their inability to understand or succeed in mathematics courses. It is unclear how negative mathematics beliefs could be related to mathematics anxiety and mathematics performance. However, one explanation could be that metacognitive processes mediate the relationship between negative mathematics beliefs and mathematics performance, as reported in several studies (for discussion see Legg and Locker Jr, 2009; Filippello et al., 2016; Buzzai et al., 2020; Gabriel et al., 2020). Future research should investigate the exact mechanism of how beliefs, metacognition, and mathematics performance interact.

The development of mathematics anxiety could also stem from interactions with parents and teachers (Berkowitz et al., 2015; Maloney et al., 2015). For example, parental pressure was found to negatively impact students' mathematics learning and mathematics anxiety (Putwain and Symes, 2011). Along these lines, one recent study found that mathematics anxiety is related to authoritarian parenting style (Macmull and Ashkenazi, 2019). In addition, some studies found that teachers' use of fear appeals (e.g., teachers telling students "work hard or you will fail") may also lead to anxiety in students (Putwain and Roberts, 2009; Putwain and Symes, 2011).

\section{DEVELOPING AN INTERVENTION FOR MATHEMATICS ANXIETY}

Until now, most schools use tutoring programs to manage mathematics anxiety and low mathematics performance. For example, Supekar et al. (2015) presented a sample of 46 grade 3 students to an intensive 8 week one-to-one tutoring program (consisted of 22 lessons of increasing difficulty; lasting 15-20 h in total). Supekar et al. (2015) found that tutoring remediated aberrant functional responses and connectivity in emotionrelated neural circuits including the basolateral amygdala. However, in this study, the decrease in mathematics anxiety following tutoring was modest. Generally speaking, tutoring is not individualized and does not target emotional and cognitive issues associated with mathematics anxiety.

There are few existing psychological intervention studies that aimed to reduce mathematics anxiety such as reappraising situations (Johns et al., 2008; Jamieson et al., 2010; Pizzie et al., 2020), expressive writing (Ramirez and Beilock, 2011; Park et al., 2014), and focused relaxation (Brunyé et al., 2013). However, these methods do not address the reasons and nature of mathematics anxiety in different individuals.

\section{A NOVEL INDIVIDUALIZED COGNITIVE BEHAVIORAL THERAPY (I-CBT) FOR MATHEMATICS ANXIETY}

Given its important relationship to mathematics performance and interest in STEM careers and that different individuals develop mathematics anxiety due to different reasons, it is important to targets the reasons underlying the development of this form of anxiety in different individuals. Along these lines, on March 13, 2008, the National Mathematics Advisory Panel presented "Foundations for Success: The Final Report of the National Mathematics Advisory Panel" to the President 
of the United States and the Secretary of Education (U.S. Department of Education). This report concluded that "anxiety about math performance is related to low math grades, failure to enroll in advanced math courses, and poor scores on standardized tests of math achievement." Accordingly, this report strongly recommended "development of promising interventions for reducing serious math anxiety." To our surprise, this is not the case yet.

Prior studies have shown CBT may be effective at reducing anxiety in general (Orbach et al., 2007; Bandelow et al., 2015; Tay et al., 2019). To our knowledge, there is only one study on the use of group CBT to effectively reduce mathematics anxiety in India (Karimi and Venkatesan, 2009). Being a group therapy, this study did not address individual differences among the participants. Here, we argue that clinicians and researchers should develop an individualized Cognitive Behavioral Therapy (i-CBT) intervention to reduce mathematics anxiety, which could, in turn, increase mathematics performance, and enhance STEM-career interests and attitudes. Below, we explain how the i-CBT can be used to ameliorate the individual factors that have led to mathematics anxiety in students.

Initially, students should undergo an initial testing to determine factors related to their mathematics anxiety, as discussed in the section above. It is expected that some students may show mathematics anxiety due to their belief, low self-esteem, or to general trait anxiety. Subsequently, if the initial screening phase show that some students suffer from general trait anxiety, then their i-CBT should include sessions that target trait anxiety. In addition, relaxation could reduce general trait anxiety as well as mathematics anxiety. Brunyé et al. (2013) divided a sample of undergraduate university students to high vs. low mathematics-anxious groups using the 30-item Mathematics Anxiety Rating Scale. Each group was given three breathing exercises, each lasting for 15 mins using relaxation-recording instructions. These exercises included focused breathing (attentional focusing on the positive sensations of the breath), unfocused breathing (thinking freely without trying to focus on anything in particular), and worry exercise (answering silently a series of anxiety-inducing questions). The results showed that focused breathing improved the accuracy of performing a mental arithmetic task and increased calmness in high but not in low mathematics-anxious group.

Individuals with emotional dysregulation due to mathematics anxiety will benefit from a practice that involves a reappraisal of their anxiety. For example, Johns et al. (2008) found that instructing participants to reappraise the anxiety they felt about mathematics led to a better mathematics performance than in a control condition. Therefore, changing emotion regulation strategies could improve mathematics anxiety and performance in individuals with emotional dysregulation. Recent studies provided support for using emotion regulation therapy with general anxiety disorders (e.g., see Mennin et al., 2018). Therefore, i-CBT techniques may ameliorate maladaptive cognitive emotion regulation strategies, which in turn may reduce mathematics anxiety and improve mathematics performance in our students. Along these lines, i-CBT should also include sessions on cognitive reappraisal to manage mathematics anxiety, which is supported by recent studies (Pizzie and Kraemer, 2021). Furthermore, expressive writing may also reduce mathematics anxiety, as it may help understand reasons underlying this form of anxiety. While this assumption was not, to our knowledge, investigated, a recent study found that expressive writing can reduce test anxiety in students (Shen et al., 2018).

We argue that i-CBT program should include sessions on identifying and modifying wrong beliefs related to mathematics anxiety and issues related to low self-esteem and self-efficacy (e.g., "girls cannot do math" or "I am not a math person"), in individuals with erroneous beliefs about mathematics practices. Standard CBT often includes sessions on changing erroneous beliefs (Pittig et al., 2019), and exiting CBT interventions have also been used to increase self-esteem (Morton et al., 2012; Sonmez et al., 2020). Further, i-CBT should include sessions to target mathematics anxiety developed due to parental pressure and/or teachers' use of fear appeals. It is possible that parental pressure and teachers' use of fear appeals may increase trait anxiety in the students and perhaps impact their self-esteem. Here it is potentially important to include parents in treatment. Some research has shown that parents can assist their children recover from anxiety in general (Hirshfeld-Becker et al., 2019), although we are not aware of any family-based interventions for mathematics anxiety.

\section{CONCLUSIONS}

In this opinion article, we show that (i) mathematics anxiety is quite common among different cultures, (ii) mathematics anxiety impacts mathematics performance and STEM careers and attitudes, and (iii) different students develop mathematics anxiety due to different reasons. Accordingly, we argue that future i-CBT program should aim to change negative affective and cognitive patterns to minimize mathematics anxiety in students. A future i-CBT intervention should aim at (i) identifying factors underlying mathematics anxiety in different students and (ii) incorporating different sessions that target factors leading to mathematics anxiety in different individuals. One benefit of individualized treatment is that it can be conducted online and can thus target a large number of students living in both urban and rural areas.

\section{AUTHOR CONTRIBUTIONS}

All authors listed have made a substantial, direct and intellectual contribution to the work, and approved it for publication.

\section{FUNDING}

This study was supported in the form of funding by NPRP-C \# Subproject (NPRP12C-33955-SP-90), which is part of a cluster project (NPRP12C-0828-190023), and from the Qatar National Research Fund (a member of Qatar foundation). The statements made herein are solely the responsibility of the authors. 


\section{REFERENCES}

Ahmed, W. (2018). Developmental trajectories of math anxiety during adolescence: associations with STEM career choice. J. Adolesc. 67, 158-166. doi: 10.1016/j.adolescence.2018.06.010

Alkan, V. (2018). A systematic review research: 'mathematics anxiety' in Turkey. Int. J. Assess. Tools Educ. 5, 567-592. doi: 10.21449/ijate.445919

Amstadter, A. (2008). Emotion regulation and anxiety disorders. J. Anxiety Disord. 22, 211-221. doi: 10.1016/j.janxdis.2007.02.004

Artemenko, C., Daroczy, G., and Nuerk, H. C. (2015). Neural correlates of math anxiety - an overview and implications. Front. Psychol. 6:1333. doi: 10.3389/fpsyg.2015.01333

Ashcraft, M. H. (2002). Math anxiety: personal, educational, and cognitive consequences. Curr. Dir. Psychol. Sci. 11, 181-185. doi: 10.1111/1467-8721.00196

Ashcraft, M. H., and Faust, M. W. (1994). Mathematics anxiety and mental arithmetic performance: an exploratory investigation. Cogn. Emot. 8, 97-125.. doi: $10.1080 / 02699939408408931$

Ashcraft, M. H., and Krause, J. A. (2007). Working memory, math performance, and math anxiety. Psychon. Bull. Rev. 14, 243-248. doi: 10.3758/BF03194059

Balmeo, C., and Fabella, F. E. (2018). Self esteem as a factor in the mathematics anxiety of grade six pupils of santolan elementary school ( $\mathrm{PhD}$ thesis). Sumulong, Cainta, Rizal. doi: 10.2139/ssrn.3184769

Baloglu, M. (1999). A comparison of mathematics anxiety and statistics anxiety in relation to general anxiety. Inf. Anal. 85, 1-30.

Bandelow, B., Reitt, M., Rover, C., Michaelis, S., Gorlich, Y., and Wedekind, D. (2015). Efficacy of treatments for anxiety disorders: a meta-analysis. Int. Clin. Psychopharmacol. 30, 183-192. doi: 10.1097/YIC.0000000000000078

Berkowitz, T., Schaeffer, M. W., Maloney, E. A., Peterson, L., Gregor, C., Levine, S. C., et al. (2015). Math at home adds up to achievement in school. Science 350, 196-198. doi: 10.1126/science.aac7427

Betz, N. E. (1978). Prevalence, distribution, and correlates of math anxiety in college students. J. Couns. Psychol. 25, 441-448. doi: 10.1037/0022-0167.25.5.441

Bieg, M., Goetz, T., Wolter, I., and Hall, N. C. (2015). Gender stereotype endorsement differentially predicts girls' and boys' trait-state discrepancy in math anxiety. Front. Psychol. 6:1404. doi: 10.3389/fpsyg.2015.01404

Brown, R., Brown, J., Reardon, K., and Merrill, C. (2011). Understanding Stem. Current Perceptions. Technol. Eng. Teach. 70, 5-9.

Brunyé, T. T., Mahoney, C. R., Giles, G. E., Rapp, D. N., Taylor, H. A., and Kanarek, R. B. (2013). Learning to relax: evaluating four brief interventions for overcoming the negative emotions accompanying math anxiety. Earn. Indiv. Diff. 27, 1-7. doi: 10.1016/j.lindif.2013.06.008

Buckley, S., Reid, K., Goos, M., Lipp, O. V., and Thomson, S. (2016). Understanding and addressing mathematics anxiety using perspectives from education, psychology and neuroscience. Aust. J. Educ. 60, 157-170. doi: 10.1177/0004944116653000

Buzzai, C., Filippello, P., Puglisi, B., Mafodda, A. V., and Sorrenti, L. (2020). The relationship between mathematical achievement, mathematical anxiety, perfectionism and metacognitive abilities in Italian students. Mediterr. J. Clin. Psychol. 8, 1-18.

Cipora, K., Szczygiel, M., Willmes, K., and Nuerk, H. C. (2015). Math anxiety assessment with the abbreviated math anxiety scale: applicability and usefulness: insights from the polish adaptation. Front. Psychol. 6:1833. doi: 10.3389/fpsyg.2015.01833

Das, S. K., Halder, U. K., and Bairagya, S. (2014). A study on self-confidence vs. mathematics anxiety in rural teenager students. Int. J. Inf. Futur. Res. 1, 50-54.

Dowker, A., Sarkar, A., and Looi, C. Y. (2016). Mathematics anxiety: what have we learned in 60 years? Front. Psychol. 7:508. doi: 10.3389/fpsyg.2016.00508

Dreger, R. M., and Aiken, L. R. (1957). The identification of number anxiety in a college population.. J. Educ. Psychol. 48, 344-351. doi: 10.1037/h0045894

Faust, M. W., Ashcraft, M. H., and Fleck, D. E. (1996). Mathematics anxiety effects in simple and complex addition. Math. Cogn. 2, 25-62 doi: 10.1080/135467996387534

Filippello, P., Spadaro, L., Sorrenti, L., Mafodda, A. V., and Drammis, L. (2016). Metacognitive processes and planning in children with dysorthography. Psicol. Clin. Dello Svilup. 1, 83-102.
Gabriel, F., Buckley, S., and Barthakur, A. (2020). The impact of mathematics anxiety on selfregulated learning and mathematical literacy. Aust. J. Educ. 64, 227-242. doi: 10.1177/0004944120947881

Gough, M. F. (1954). Mathemaphobia: causes and treatments. Clear. House 28, 290-294. doi: 10.1080/00098655.1954.11476830

Hart, S. A., and Ganley, C. M. (2019). The nature of math anxiety in adults: prevalence and correlates. J. Numer. Cogn. 5, 122-139. doi: 10.5964/jnc.v5i2. 195

Hartwright, C. E., Looi, C. Y., Sella, F., Inuggi, A., Santos, F. H., GonzalezSalinas, C., et al. (2018). The neurocognitive architecture of individual differences in math anxiety in typical children. Sci. Rep. 8, 8500. doi: 10.1038/s41598-018-26912-5

Hembree, R. (1990). The nature, effects, and relief of mathematics anxiety. J. Res. Math. Educ/ 21, 33-46. doi: 10.2307/749455

Hirshfeld-Becker, D. R., Henin, A., Rapoport, S. J., Wilens, T. E., and Carter, A. S. (2019). Very early family-based intervention for anxiety: two case studies with toddlers. Gen. Psychiatr. 32:e100156. doi: 10.1136/gpsych-2019-100156

Jameson, M. M., and Fusco, B. R. (2014). Math anxiety, math self-concept, and math self-efficacy in adult learners compared to traditional undergraduate students. Adult Educ. Q. 64, 306-322. doi: 10.1177/0741713614541461

Jamieson, J., Mendes, W. B., Blackstock, E., and Schmader, T. (2010). Turning the knots in your stomach into bows: reappraising arousal improves performance on the GRE.. J. Exp. Soc. Psychol. 46, 208-212. doi: 10.1016/j.jesp.2009.08.015

Johns, M., Inzlicht, M., and Schmader, T. (2008). Stereotype threat and executive resource depletion: examining the influence of emotion regulation. J. Exp. Psychol. General 137, 691-705. doi: 10.1037/a0013834

Karimi, A., and Venkatesan, S. (2009). Cognitive behavior group therapy in mathematics anxiety. J. Indian Acad. Appl. Psychol. 35, 299-303.

Kazelskis, R., Reeves, C., Kersh, M. E., Bailey, G., Cole, K., et al. (2000). Mathematics anxiety and test anxiety: separate constructs? J. Exp.Educ 68, 137-146. doi: 10.1080/00220970009598499

Klein, E., Bieck, S. M., Bloechle, J., Huber, S., Bahnmueller, J., Willmes, K., et al. (2019). Anticipation of difficult tasks: neural correlates of negative emotions and emotion regulation. Behav. Brain Funct. 15, 4. doi: 10.1186/s12993-019-0155-1

Krinzinger, H., Kaufmann, L., and Willmes, K. (2009). Math anxiety and math ability in early primary school years. J. Psychoeduc. Assess. 27, 206-225. doi: $10.1177 / 0734282908330583$

Lauer, J. E., Esposito, A. G., and Bauer, P. J. (2018). Domain-specific anxiety relates to children's math and spatial performance. Dev. Psychol. 54, 2126-2138. doi: $10.1037 /$ dev0000605

Legg, A. M., and Locker Jr, L. (2009). Math performance and its relationship to math anxiety and metacognition. N. Am. J. Psychol. 11, 471-486.

Lukowski, S. L., DiTrapani, J., Rockwood, N. J., Jeon, M., Thompson, L. A., and Petrill, S. A. (2019b). Etiological distinction across dimensions of math anxiety. Behav. Genet. 49, 310-316. doi: 10.1007/s10519-018-09946-3

Lukowski, S. L., DiTrapani, J. B., Jeon, M., Wang, Z., Schenker, V. J., Doran, M. M., et al. (2019a). Multidimensionality in the measurement of math-specific anxiety and its relationship with mathematical performance. Learn. Individ. Differ. 70, 228-235. doi: 10.1016/j.lindif.2016.07.007

$\mathrm{Ma}, \mathrm{X}$. (1999). A meta-analysis of the relationship between anxiety toward mathematics and achievement in mathematics. J. Res. Math. Educ. 30, 520-540. doi: $10.2307 / 749772$

Macmull, M. S., and Ashkenazi, S. (2019). Math anxiety: the relationship between parenting style and math self-efficacy. Front. Psychol. 10:1721. doi: 10.3389/fpsyg.2019.01721

Maloney, E. A., Ramirez, G., Gunderson, E. A., Levine, S. C., and Beilock, S. L. (2015). Intergenerational effects of parents' math anxiety on children's math achievement and anxiety. Psychol. Sci. 26, 1480-1488. doi: $10.1177 / 0956797615592630$

McDonough, I. M., and Ramirez, G. (2018). Individual differences in math anxiety and math self-concept promote forgetting in a directed forgetting paradigm. Learn. Individ. Differ. 64, 33-42. doi: 10.1016/j.lindif.2018.04.007

Megreya, A. M., Szucs, D., and Moustafa, A. A. (2021). The Abbreviated Science Anxiety Scale: Psychometric properties, gender differences and associations with test anxiety, general anxiety and science achievement. PLoS ONE 16:e245200. doi: 10.1371/journal.pone.024 5200 
Mennin, D. S., Fresco, D. M., O’Toole, M. S., and Heimberg, R. G. (2018). A randomized controlled trial of emotion regulation therapy for generalized anxiety disorder with and without co-occurring depression. J. Consult. Clin. Psychol. 86, 268-281. doi: 10.1037/ccp0000289

Morton, L., Roach, L., Reid, H., and Stewart, S. H. (2012). An evaluation of a CBT group for women with low self-esteem. Behav. Cogn. Psychother. 40, 221-225. doi: $10.1017 /$ S1352465811000294

Moustafa, A. A., Porter, A., and Megreya, A. M. (2020). Mathematics anxiety and cognition: an integrated neural network model. Rev. Neurosci. 31, 287-296. doi: 10.1515/revneuro-2019-0068

Moustafa, A. A., Tindle, R., Ansari, Z., Doyle, M. J., Hewedi, D. H., and Eissa, A. (2017). Mathematics, anxiety, and the brain. Rev. Neurosci. 28, 417-429. doi: 10.1515/revneuro-2016-0065

Namkung, J. M., Peng, P., and Lin, X. (2019). The relation between mathematics anxiety and mathematics performance among school-aged students: a metaanalysis. Rev. Educ. Res. 89, 459-496. doi: 10.3102/0034654319843494

OECD. (2013). PISA 2012 results: ready to learn: students' engagement, drive and self-beliefs (Volume III). Paris, France: OECD. doi: 10.1787/9789264201170-en

O'Leary, K., Fitzpatrick, C. L., and Hallett, D. (2017). Math anxiety is related to some, but not all, experiences with math. Front. Psychol. 8:2067. doi: 10.3389/fpsyg.2017.02067

Orbach, G., Lindsay, S., and Grey, S. (2007). A randomised placebo-controlled trial of a self-help Internet-based intervention for test anxiety. Behav. Res. Ther. 45, 483-496. doi: 10.1016/j.brat.2006.04.002

Paechter, M., Macher, D., Martskvishvili, K., Wimmer, S., and Papousek, I. (2017). Mathematics anxiety and statistics anxiety. shared but also unshared components and antagonistic contributions to performance in statistics. Front. Psychol. 8:1196. doi: 10.3389/fpsyg.2017.01196

Park, D., Ramirez, G., and Beilock, S. (2014). The role of expressive writing in math anxiety. J. Exp. Psychol. Appl. 20, 103-111. doi: 10.1037/xap0000013

Pittig, A., Kotter, R., and Hoyer, J. (2019). The struggle of behavioral therapists with exposure: self-reported practicability, negative beliefs, and therapist distress about exposure-based interventions. Behav. Ther. 50, 353-366. doi: 10.1016/j.beth.2018.07.003

Pizzie, R., and Kraemer, D. J. M. (2018). The influence of emotion regulation on arousal and performance in math anxiety. OSF Preprints. doi: 10.31219/osf.io/f3d59

Pizzie, R. G., and Kraemer, D. J. M. (2021). The association between emotion regulation, physiological arousal, and performance in math anxiety. Front. Psychol. 12:639448. doi: 10.3389/fpsyg.2021.639448

Pizzie, R. G., McDermott, C. L., Salem, T. G., and Kraemer, D. J. M. (2020). Neural evidence for cognitive reappraisal as a strategy to alleviate the effects of math anxiety. Soc. Cogn. Affect. Neurosci. 15, 1271-1287. doi: 10.1093/scan/nsaa161

Putwain, D. W., and Roberts, C. M. (2009). The development of an instrument to measure teachers' use of fear appeals in the GCSE classroom. Br. J. Educ. Psychol. 79(Pt 4), 643-661. doi: 10.1348/000709909X426130

Putwain, D. W., and Symes, W. (2011). Teachers' use of fear appeals in the mathematics classroom: worrying or motivating students? Br. J. Educ. Psychol. 81(Pt 3), 456-474. doi: 10.1348/2044-8279.002005

Ramirez, G., and Beilock, S. L. (2011). Writing about testing worries boosts exam performance in the classroom. Science 331, 211-213. doi: 10.1126/science.1199427

Ramirez, G., Shaw, S. T., and Maloney, E. A. (2018). Math anxiety: past research, promising interventions, and a new interpretation framework. Educ. Psychol. 53, 145-164 doi: 10.1080/00461520.2018.1447384
Russo, P. M., Barbaranelli, C., and Caponera, E. (2014). The influence of broad and specific personality traits on mathematics achievement. Pers. Individ. Dif. 60:S73. doi: 10.1016/j.paid.2013.0 7.327

Shen, L., Yang, L., Zhang, J., and Zhang, M. (2018). Benefits of expressive writing in reducing test anxiety: a randomized controlled trial in Chinese samples. PLOS ONE 13, e0191779. doi: 10.1371/journal.pone.019 1779

Sonmez, N., Romm, K. L., Ostefjells, T., Grande, M., Jensen, L. H., Hummelen, B., et al. (2020). Cognitive behavior therapy in early psychosis with a focus on depression and low self-esteem: a randomized controlled trial. Compr. Psychiatry 97:152157. doi: 10.1016/j.comppsych.2019.152157

Supekar, K., Iuculano, T., Chen, L., and Menon, V. (2015). Remediation of childhood math anxiety and associated neural circuits through cognitive tutoring. J. Neurosci. 35, 12574-12583. doi: 10.1523/JNEUROSCI.0786-15.2015

Suveg, C., Jones, A., Davis, M., Jacob, M. L., Morelen, D., Thomassin, K., et al. (2018). Emotion-focused cognitive-behavioral therapy for youth with anxiety disorders: a randomized trial. J. Abnorm. Child Psychol. 46, 569-580. doi: 10.1007/s10802-017-0319-0

Tay, K. W., Subramaniam, P., and Oei, T. P. (2019). Cognitive behavioural therapy can be effective in treating anxiety and depression in persons with dementia: a systematic review. Psychogeriatrics 19, 264-275. doi: 10.1111/psyg.12391

Tsupros, N., Kohler, R., and Hallinen, J. (2009). STEM education: a project to identify the missing components. Intermediate Unit 1: Center for STEM Education and Leonard Gelfand Center for Service Learning and Outreach. Retrieved from Carnegie Mellon University, Pennsylvania.

Turk, C. L., Heimberg, R. G., Luterek, J. A., Mennin, D. S., and Fresco, D. M. (2005). Emotion dysregulation in generalized anxiety disorder: a comparison with social anxiety disorder. Cogn. Ther. Res. 29, 89-106. doi: 10.1007/s10608-005-1651-1

Walsh, K. A. (2008). The relationship among mathematics anxiety, beliefs about mathematics, mathematics self-efficacy, and mathematics performance in associate degree nursing students. Nurs. Educ. Perspect. 29, 226-229.

Zhang, J., Zhao, N., and Kong, Q. P. (2019). The relationship between math anxiety and math performance: a meta-analytic investigation. Front. Psychol. 10:1613. doi: 10.3389/fpsyg.2019.01613

Conflict of Interest: The authors declare that the research was conducted in the absence of any commercial or financial relationships that could be construed as a potential conflict of interest.

Publisher's Note: All claims expressed in this article are solely those of the authors and do not necessarily represent those of their affiliated organizations, or those of the publisher, the editors and the reviewers. Any product that may be evaluated in this article, or claim that may be made by its manufacturer, is not guaranteed or endorsed by the publisher.

Copyright (C) 2021 Moustafa, Al-Emadi and Megreya. This is an open-access article distributed under the terms of the Creative Commons Attribution License (CC BY). The use, distribution or reproduction in other forums is permitted, provided the original author(s) and the copyright owner(s) are credited and that the original publication in this journal is cited, in accordance with accepted academic practice. No use, distribution or reproduction is permitted which does not comply with these terms. 